\title{
Non-communicable diseases diagnosed in a health care service for dock workers: a case study in a seaport of Brazil
}

\author{
Marta Regina Cezar-Vaz, Marlise Capa Verde de Almeida, Clarice Alves Bonow, Laurelize Pereira \\ Rocha, Anelise Miritz Borges, Luana de Oliveira Severo \\ Nursing School, Federal University of Rio Grande (FURG), Brazil \\ Correspondence: Marta Regina Cezar-Vaz. Address: Rua General Osório, s/no. Campus da Saúde. Centro. Rio Grande, \\ RS, Brazil. Email: cezarvaz@vetorial.net.
}

Received: J une 29, 2012

DOI : $10.5430 /$ jnep.v3n6p35

Online Published: December 26, 2012

Accepted: November 27, 2012

URL: http://dx.doi.org/10.5430/jnep.v3n6p35

\begin{abstract}
Background: Dock workers are important for world economic growth. They develop work where they are exposed to risk factors for non-communicable diseases. Non-communicable diseases are characterized as disorders that affect the general population and in recent decades the number of deaths worldwide has been considered significant. The aims of this study have been to identify non-communicable diseases that affect dock workers, according to records from the Medical Outpatient Clinic for Dock Workers.

Methods: Quantitative and exploratory study. Data were collected from all medical care files of dock workers in the period 2000 to 2009. A predetermined form was used, focusing on clinical data and diagnoses of non-communicable diseases. Descriptive data analysis was performed.

Results: Data were collected from 953 medical care records. The population was predominantly male (90.47\%) and the predominant age of workers was below 50. The most common non-communicable diseases were hypertension (8.3\%); obesity (5.6\%); diabetes mellitus (3\%); acute myocardial infarction (0.5\%).

Conclusion: The results showed hypertension, obesity and diabetes as the more prevalent non-communicable diseases. Occupational health nurses possess the theoretical and practical knowledge to organize a process of care that includes prevention and promotes health strategies appropriate for the labour reality of this group of workers.
\end{abstract}

\section{Key words}

Non-communicable disease, Nursing, Occupational health

\section{I ntroduction}

Non-communicable diseases (NCDs) are characterized by non-infectious multiple etiology, which have long latency periods, prolonged course and capable of producing functional disabilities. They are responsible for a significant number of deaths in the world in recent decades, reaching 35 million each year, of which $80 \%$ occur in the population of countries of low and middle income ${ }^{[1,2]}$. 
The World Health Organization defines and classifies NCDs into four groups: cardiovascular diseases, chronic respiratory diseases, cancer cases and diabetes mellitus. In addition to these, mental and neurological disorders, oral diseases, bone and joint diseases, genetic disorders, eye and hearing diseases are also considered ${ }^{[2,3]}$.

Cardiovascular diseases are represented by infarction, stroke, cardiac arrhythmias, ischemia, congestive heart failure and angina. One of the pathological conditions that converge on the development of this group of diseases is the presence of dyslipidemia and atherosclerosis, which influence blood pressure and therefore cause cardiac abnormalities ${ }^{[4]}$. Chronic respiratory diseases are mainly represented by rhinitis, asthma and chronic obstructive pulmonary disease (COPD), which can affect both upper and lower airways, affecting thousands of people worldwide and which are increasing among children and the elderly ${ }^{[5]}$. Cancer comprises a process of interaction between risk factors and environmental legacy, identified both among women, highlighting the cases of breast and cervical cancer, as well as in the general population, in cases arising from exposure to physical, biological and chemical agents ${ }^{[6]}$.

Diabetes Mellitus is a metabolic disorder related to hyperglycemia and complications such as systemic dysfunction and failure of various organs, such as the eyes, kidneys, nerves, brain, heart and blood vessels. It is a common disease of increasing incidence, which includes among its possible consequences significant loss in quality of life, related to the possibility of developing kidney failure, lower limb amputation, blindness and cardiovascular disease ${ }^{[7]}$.

All NCDs characterized by significant interference in the quality of life and bodily physiological function of the affected individual and with the demands of work added to these conditions ${ }^{[8]}$, reduce worker productivity, both in the work environment and in personal life, reflecting negatively in social and economic sectors. In this sense it is important to identify the occurrence of these pathological groups between different branches of workers, in the belief that the implementation of preventive measures meets the professional and personal demands of the workers. In this study, the context of port work is presented, which is performed by a significant number of workers who work in support of local and world economic growth and whose work demands have become increasingly intense. In Brazil, the ports are responsible for approximately 85\% of export by sea, and in 2011, the Port of Rio Grande was the fourth largest in the export of products, totaling around 480 thousand tons ${ }^{[4]}$.

The work routine at this pace influences in the development of NCDs of dock workers (DWs) because they are key to the movement of goods and vessels. Studies have identified the occurrence of certain NCDs in this environment, such as respiratory diseases, self-reported by $20.92 \%$ of 306 DW, and cardiovascular, self-reported by $19.14 \%$ in the same sample[9]. Besides these, the self-reference of hypertension among $10 \%$ of a total of 60 workers was identified among stevedores of a northeastern port of Brazil while $8.4 \%$ could not answer if they had the disease. When asked about diabetes, $6.7 \%$ reported a present condition while $13.3 \%$ did not know if they were diabetic ${ }^{[10]}$.

There is mutual understanding that NCDs have a complex and diverse nature, including various risk and protective factors that can contribute to maximize or minimize their potential aggression on the human body, respectively. Therefore, it is emphasized that the analysis of this type of information allows nurses to plan through clinical evidence ${ }^{[11]}$, made possible through the diagnosis in a group of workers, as in the specific case, DWs. Thus, the research questions are: what are the NCDs that affect the DWs? Aim: to identify NCDs that affect DWs health and check association between the diseases, age and service time of DWs.

\section{Methodology}

This study is part of a larger research project entitled "Health, Risks and Occupational Diseases: an integrated study in different work environments", which is being developed by the Laboratory of Socio-environmental Process Studies and Collective Production of Health (LAMSA) research group of the School of Nursing of the Federal University of Rio Grande (FURG). The research project, which this research is part of, was approved by the Research Ethics Committee of 
the Federal University of Rio Grande (Universidade Federal do Rio Grande - FURG) (Opinion No 40-2010 - Process No 23116.003856/2010-15).

\subsection{Study design}

Cross-sectional quantitative, exploratory and retrospective study, developed from August to December 2010 in Órgão Gestor da Mão-de-Obra Portuária (OGMO) of a municipality in southern Rio Grande do Sul.

\subsection{Study population}

The study included data from 953 medical records of the Medical Outpatient's Clinic for Dock Workers, affiliated to OGMO. Data collection was accomplished from a predetermined form and structured and prepared by LAMSA by theoretical documents of the Ministry of Health of Brazil (MS) and the World Health Organization (WHO) / Pan American Health Organization (OPS) ${ }^{[3,12]}$ for identifying clinical diagnoses.

The established criteria for data selection were: be an officially registered DW in OGMO; have medical records that contain information on health from 2000 to 2009 and; the description of chronic diseases diagnoses.

\subsection{Demographic and personal variables}

Demographic and personal variables addressed in this study were sex, age, work time and variables on lifestyle (physical activity, use of drugs, alcohol and tobacco).

\subsection{Clinical variables}

Between sessions of the questionnaire, the session on clinical diagnoses was prioritized, which facilitated obtaining registration of NCD, performed by professionals working in the service (occupational physician and allied health personnel). Medical diagnoses were grouped according to the International Statistical Classification of Disease and Related Health Problems 10th Revision ${ }^{[13]}$, as follows: Group 1 - Diseases of the circulatory system; Group 2 Endocrine, nutritional and metabolic disease; Group 3 - Disease of the respiratory system; Group 4 - Neoplasm, adding also other NCDs the health research of which is prioritized in Brazil as: Group 5 - Diseases of the musculoskeletal system and connective tissue, represented by osteoarticular disease; Group 6 - Diseases of the blood and blood-forming organs and certain disorders involving the immune mechanism, and Group 7 - Diseases of the genitourinary system ${ }^{[13]}$.

\subsection{Data analysis}

Data organization and analysis included information typed in EPINFO 6.04 software, permitting double data entry with a view to reliability. For analysis purposes, Statistical Package for the Social Sciences (SPSS) software, version 19.0 was used. Frequency analysis was performed and the preparation of contingency tables to perform the chi-square test.

For statistical analysis, clinical data were presented as categorical qualitative variables (yes and no) and dichotomized. The continuous variables, age and work time, were dichotomized, based on the median of each variable (Age: 50 years; Work time: 15 years).

\section{Results}

Data were collected from 953 records. The male population is 952 subjects (90.4\%); 496 subjects (51.6\%) have age under 50 years old. With regard to work time in dock ports, 492 (51.6\%) of workers had under 19 years. Table 1 presents the most frequent NCDs identified (group 1 - Diseases of the circulatory system; group 2 - Endocrine, nutritional and metabolic disease; group 3 - Disease of the respiratory system; group 4 - Neoplasm) as age and work time: 


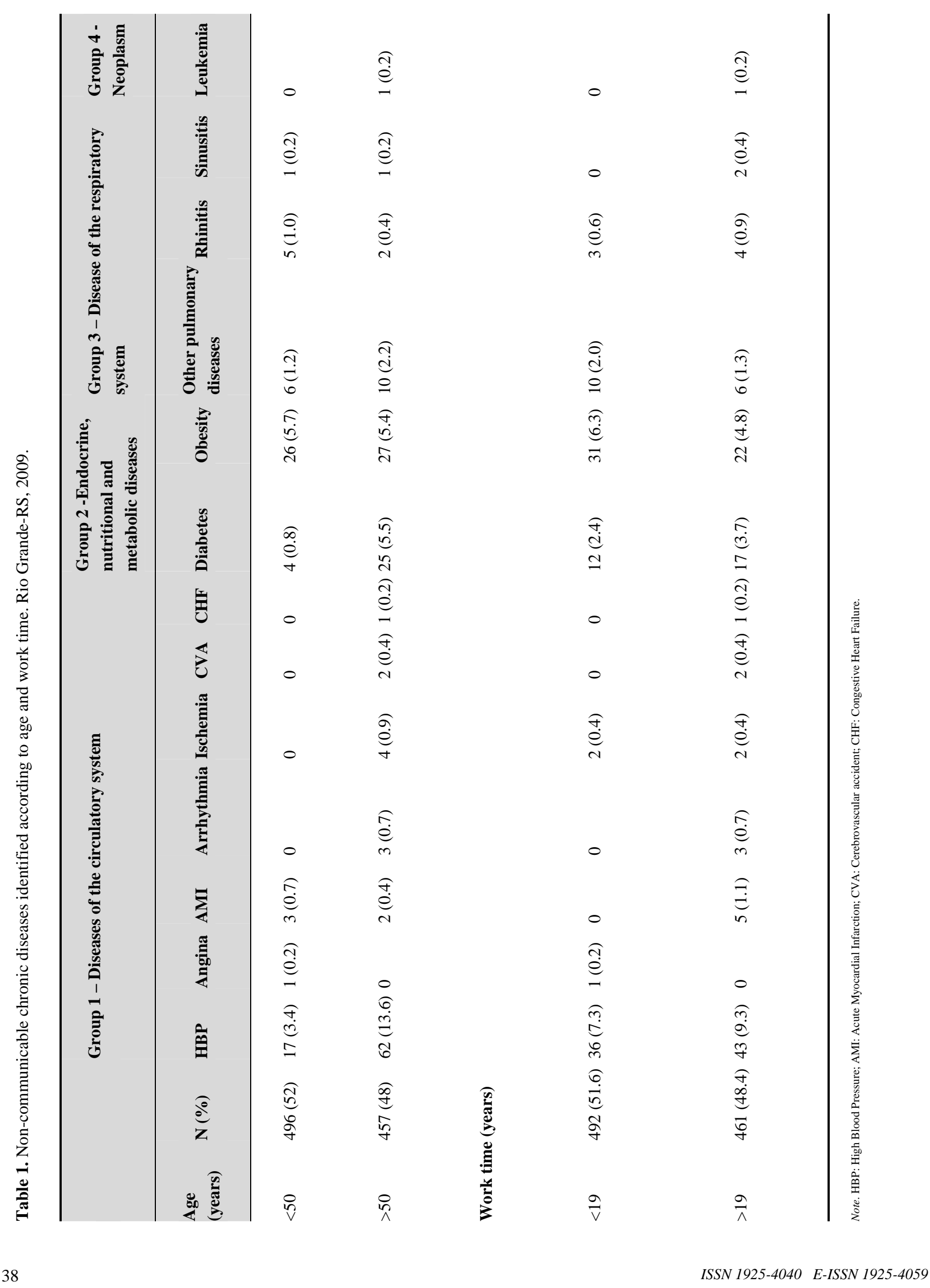


From group 1, hypertension had 79 occurrences (8.3\%); from group 2, obesity had 53 (11.1\%), from group 3, pulmonary diseases had 16 occurrences (1.7\%), from group 4, leukemia had one occurrence $(0.2 \%)$.

Statistical analysis showed dependency relationship between the variables of hypertension and age $(p=0.000)$, and diabetes and age $(p=0.000)$. The other variables were not statistically significant.

From group 5, arthritis had three cases (0.3\%) and unspecified osteoarthritis, 15 cases (1.4\%); from group 6, anemia had 4 cases $(0.4 \%)$ and thrombocytopenia had one case $(0.1 \%)$; from group 7 , nephrolithiasis had three cases $(0.3 \%)$.

Among the information obtained, data is highlighted on lifestyle habits of some workers, which may be increasing with the occurrence of NCD. Thus Table 2 shows the relation between the occurrence of NCD and some health habits identified in the medical records. In the statistical analysis above the variables showed no significant association.

Table 2. Relation between occurrence of non-communicable diseases and lifestyle habits.

\begin{tabular}{|c|c|c|c|c|c|c|c|c|c|}
\hline & & \multicolumn{2}{|c|}{ Alcoholism } & \multicolumn{2}{|c|}{ Smoke } & \multicolumn{2}{|c|}{ Drugs user } & \multicolumn{2}{|c|}{ Exercise } \\
\hline & & $\mathbf{N}$ & (\%) & $\mathbf{N}$ & $(\%)$ & $\mathbf{N}$ & (\%) & $\mathbf{N}$ & $(\%)$ \\
\hline \multirow{7}{*}{ Cardiovascular diseases } & Hypertension disease & 10 & 17.2 & 01 & 5.3 & 01 & 5.3 & 08 & 15.4 \\
\hline & Angina & 01 & 0.1 & 00 & 00 & 00 & 00 & 00 & 00 \\
\hline & Acute myocardial infarction & 01 & 1.7 & 00 & 00 & 00 & 00 & 00 & 00 \\
\hline & Arrhythmia & 00 & 00 & 00 & 00 & 00 & 00 & 00 & 00 \\
\hline & Ischemia & 00 & 00 & 00 & 00 & 00 & 00 & 01 & 1.9 \\
\hline & CVA & 00 & 00 & 00 & 00 & 00 & 00 & 01 & 1.9 \\
\hline & $\mathrm{CHF}$ & 00 & 00 & 00 & 00 & 00 & 00 & 00 & 00 \\
\hline \multirow{2}{*}{$\begin{array}{l}\text { Endocrine, nutritional and } \\
\text { metabolic disease }\end{array}$} & Diabetes mellitus & 02 & 3.4 & 00 & 00 & 00 & 00 & 02 & 3.8 \\
\hline & Obesity & 01 & 5.3 & 16 & 6.2 & 01 & 5.3 & 06 & 11.5 \\
\hline \multirow{3}{*}{ Respiratory disease } & $\begin{array}{l}\text { Other pulmonary diseases } \\
\text { (Asthma and COPD) }\end{array}$ & 02 & 3.4 & 00 & 00 & 00 & 00 & 02 & 3.8 \\
\hline & Rhinitis & 00 & 00 & 00 & 00 & 00 & 00 & 00 & 00 \\
\hline & Sinusitis & 00 & 00 & 00 & 00 & 00 & 00 & 00 & 00 \\
\hline Cancer & Leukemia & 00 & 00 & 00 & 00 & 00 & 00 & 00 & 00 \\
\hline
\end{tabular}

\section{Discussion}

The results show a predominantly male population, of which 203 workers (21.3\%) is affected by NCDs, a significant number compared to the rates of mortality from these diseases in the world, which reached $63 \%$ in $2008{ }^{[12]}$. The diseases with the highest incidence in the study population were hypertension, obesity and diabetes mellitus, which together provide the deposition of body fat and resistance to insulin, (the main features of the metabolic syndrome), which in turn raises cardiovascular risks. In this sense, the diseases identified by cause damage, and appropriate preventative strategies have been demonstrated to limit these diseases.

In this context, the exposure to psychosocial stress in the workplace may be considered added risk factors for cardiovascular diseases. High blood pressure, for example, may present as secondary hypertension due to occupational stress situations, promoting physical and mental changes causing somatic and cardiovascular disorders ${ }^{[15]}$. The port environment presents unique characteristics such as lifting heavy loads, the maintenance of ships and products, inspection of documents and personnel, among others, which require physical effort, that provoke stress and influence metabolic conditions. Consequently, stress can be conceptualized as one of a set of physical and psychological symptoms (including fatigue, irritability, aggression and anxiety), that cause hypertension ${ }^{[16]}$. 
Shift and rotational work are also characteristics that influence chronic health conditions because, lack of exercise, and extensive working hours, may also constitute risk factors for cardiovascular diseases, such as AMI ${ }^{[17]}$. The port routine requires variability of working hours, which indicates that the work routine may be influencing pathological development.

Therefore, these factors influence the endocrine and metabolic conditions of workers. This includes obesity, which can also be considered a NCD because it is a risk factor for the development of NCDs ${ }^{[18]}$. This pathology is associated with the individual's eating habits and may effect work efficiency, which through absenteeism and increased financial costs resulting from metabolic disturbance to the worker ${ }^{[19]}$.

Moreover, the nature of temporary work of DWs impedes the usual practice of the employer monitoring of the employee meals provided to the employee by the employer. This may be leading to inadequate eating habits by the use of street traders, such as those located on the outskirts of the port. Poor nutrition enhances diabetes, which was also is a significant disease among DWs. This is a major public health problem in Brazil, which is debilitating and causes high morbidity and mortality. Specifically, diabetes mellitus is not considered a disease related to work, however, work factors as demonstrated above including food choices, lack of exercise and stress within the shiftwork environment may increase the DW risk factors. Diabetes mellitus leads to reduction in work, early retirement, and premature mortality ${ }^{[20]}$ and increases the costs of health care and social costs arising from complications of the disease.

The group of chronic respiratory diseases, among which rhinitis was prominent in the study population, characterized by the presence of nasal symptoms associated with high or low occupational exposure to molecular agents and/or irritants ${ }^{\text {[21] }}$. Sinusitis was also predominant, characterized by inflammation of paranasal sinuses due to infections caused by viruses, bacteria or fungi or even by acute or chronic allergic reactions ${ }^{[5]}$. In the port environment, many employees work indoors, inside ships and containers, which, in addition to other workplaces, increases exposure to pollutants that affect health. Factors such as poor ventilation and inefficient exchange of air produce higher concentrations of carbon dioxide and dust, which, in turn, increases the occurrence of asthma and allergies, such as rhinitis ${ }^{[2]}$. Thus, the importance of the use of protective devices and controlling dust levels is emphasized as this may reduce the prevalence of respiratory NCDs ${ }^{[23]}$.

Cases of cancer identified as NCDs are also highlighted. In relation to the occupation, the occurrence of this type of disease is strongly associated with environmental factors, such as exposure to chemicals, but it is also linked to environmental factors, such as consumption of processed food, drugs, alcohol, tobacco, household products and cultural environment, referring to the customs and daily habits of life ${ }^{[24]}$. Thus, the interrelationship between NCDs is presented, which enables the institution of similar strategies in health, covering prevention and alleviation of the symptoms involved.

Even personal habits, like drug use, alcohol consumption and smoking, (health information obtained in this study), cause substantial effects on metabolism, producing changes related to the disease groups discussed. In this sense, studies show the use of these substances ${ }^{[10]}$ and performance in the workplace under the influence of these substances, such as alcohol and marijuana ${ }^{[24]}$. This refers to the possibility of interaction between the harmful effects of drugs and NCDs, directly interfering in the lives of workers and their productivity in the workplace. For this and other reasons, modifiable habits regarding physical activity, smoking, drinking and eating are the key action items for the prevention and control of NCDs ${ }^{[1,2]}$.

In this perspective, the role of the occupational health nurse can provide concrete and reliable information about the consequences of these habits in the daily work of the DWs, improve safety and enhance the professional profile as well as combating the diseases. As an example, physical activity reduces the incidence of NCDs, such as cardiovascular disease and diabetes ${ }^{[1,2]}$. Thus, guidance on health should be planned in accordance with the recommendations, such as the suggestion of 150 minute weekly activities, associated with healthy eating ${ }^{[2]}$, which can be prescribed based on daily food intake, involving the worker in the plan of action. 
Besides these recommendations, the orientation of quitting smoking and alcohol consumption is also considered important for protecting people and the environment from tobacco smoke and also involves the prohibition of smoking in public places, the operation of machinery and vehicles under the influence of alcohol and the impact of harmful alcohol use in relation to other health conditions, such as liver cancer and cardiovascular disease ${ }^{[1,2]}$.

Therefore, it is important to strengthen the occupational health professional valuable skills and knowledge to manage these health problems with the aim of not affecting the work performance and personal experience of the workers; increasing satisfaction and adherence to the treatment plan and making the worker pro-active under their care ${ }^{[11]}$.

Limitations of this study are acknowledged, including the research for health information from secondary data produced by medical records and not all records contained information related to lifestyle, which makes it difficult to relate statistically NCDs and lifestyle habits. However, being a documentary and retrospective study, it has been possible to produce a survey of clinical characteristics that provide information for future interventional studies of nursing in this environment.

\section{Conclusions}

The study revealed a significant occurrence of NCDs among DWs. These results highlight the need for further studies on the subject in the study population. Cardiovascular, respiratory and metabolic diseases were more prevalent, which can facilitate health action in order to submit similar intervention strategies, focused on lifestyle habits.

Thus, it can be concluded that the port environment constitutes a productive field for the implementation of health care that can promote the mitigation of risk factors for pathological development through re-education guidelines for food and the encouragement of physical activity. It is of mutual belief that knowledge of this reality provides a specific example to encourage the development of occupational health and social welfare nursing projects and teaching-learning projects in the education of future professionals.

\section{Acknowledgments}

This study was supported by Conselho Nacional de Desenvolvimento Científico e Tecnológico (CNPq).

\section{References}

[1] WORLD HEALTH ORGANIZATION. World Health Organization: Global status report on noncommunicable diseases. Geneva: World Health Organization; 2011.

[2] WORLD HEALTH ORGANIZATION. 2008-2013 Action Plan for the global strategy for the prevention and control of noncommunicable diseases: prevent and control cardiovascular diseases, cancers, chronic respiratory diseases and diabetes. Geneva: World Health Organization; 2008.

[3] BRASIL. Ministério da Saúde. Secretaria de Vigilância à Saúde. Secretaria de Atenção à Saúde. Diretrizes e recomendações para o cuidado integral de doenças crônicas não-transmissíveis: promoção da saúde, vigilância, prevenção e assistência / Ministério da Saúde, Secretaria de Vigilância à Saúde, Secretaria de Atenção à Saúde. - Brasília: Ministério da Saúde, 2008.

[4] PAHO. Pan American Health Organization. Technical reference document on Non-communicable Disease Prevention and Control [online] / Pan American Health Organization/ World Health Organization, 2011, 38p.

[5] BRASIL. Ministério da Saúde. Secretaria de Atenção à Saúde. Departamento de Atenção Básica. Doenças respiratórias crônicas/ Ministério da Saúde, Secretaria de Atenção à Saúde, Departamento de Atenção Básica. - Brasília : Ministério da Saúde, 2010. 160p.

[6] BRASIL. Ministério da Saúde. Instituto Nacional de Câncer José Alencar Gomes da Silva. Diretrizes para a vigilância do câncer relacionado ao trabalho . Área de Vigilância do Câncer relacionado ao Trabalho e ao Ambiente. Rio de Janeiro : Inca, 2012.187 p.

[7] BRASIL. Ministério da Saúde. Secretaria de Atenção à Saúde. Departamento de Atenção Básica. Diabetes Mellitus. Brasília: 2006. $64 \mathrm{p}$. 
[8] WANG X-S, ARMSTRONG MEG, CAIRNS BJ, KEY TJ, TRAVIS RC. Shift work and chronic disease: the epidemiological evidence. Occup Med (Lond). 2011; 61:78-89. PMid:21355031 http://dx.doi.org/10.1093/occmed/kqr001

[9] CEZAR-VAZ MR, SOARES JFS, ALMEIDA MCV, CARDOSO LS, BONOW CA. Self-referred illnesses related to work in self-employed port workers. Cienc Cuid Saude. 2010; 9(4):774-781.

[10] CAVALCANTE FFG et al. Occupational risks among dock workers in the Port of Mucuripe, Fortaleza, Brazil. Ciênc. saúde coletiva [online]. 2005; 10: suppl.:101-110.

[11] ALLEYNE G; HANCOCK C; HUGHES P. Chronic and non-communicable diseases: a critical challenge for nurses globally. Int Nurs Rev. 2011; 58(3): 328-331. PMid:21848778 http://dx.doi.org/10.1111/j.1466-7657.2011.00912.x

[12] BRASIL. Ministério da Saúde do Brasil. Organização Pan-Americana da Saúde no Brasil. Doenças relacionadas ao trabalho: manual de procedimentos para os serviços de saúde. Normas e Manuais Técnicos; Brasília: 2001. p.580.

[13] WORLD HEALTH ORGANIZATION. International Statistical Classification of Disease and Related Health Problems. Geneva: World Health Organization; 2010.

[14] BRASIL. Ministério da Saúde. Agenda nacional de prioridades de pesquisa em saúde. 2a ed. Brasília: Editora do Ministério da Saúde, 2008. p. 68.

[15] COUTO HA, VIEIRA FLH, LIMA EG. Work stress and arterial hypertension. Rev Bras Hipertens. 2007; 14(2): 112-115.

[16] PINTO E SILVA E. Listening to stressed workers as a strategy for professional formation enhancement. Aletheia 29. $2009 ; 43-56$.

[17] GIODA A; AQUINO NETO FR. Comments on studies of industrial and non-industrial environments in Brazil: a comparative approach. Cad. Saúde Pública [online]. 2003; 19(5): 1389-1397. http://dx.doi.org/10.1590/S0102-311X2003000500017

[18] FELIPE-DE-MELO ERT; SILVA RCR; ASSIS AMO; PINTO EJ. Factors associated with metabolic syndrome in administrative workers in the oil industry. Ciência \& Saúde Coletiva. 2011; 16(8): 3443-3452. PMid:21860944

[19] TUNCELI K, LI K, WILLIAMS LK. Long-term effects of obesity on employment and work limitations among U.S. Adults, 1986 to 1999. Obesity (Silver Spring). 2006; 14(9): 1637-46. PMid:17030975 http://dx.doi.org/10.1038/oby.2006.188

[20] TAVARES DMS; REIS NA; DIAS FA; LOPESFAM. Diabetes mellitus: occurrence of risk factors and care among nursing workers. Acta paul. enferm. 2010; 23(5): 671-676.

[21] GALVÃO CES. Occupational asthma and rhinitis - immunoallergic view. Rev. bras. alerg. imunopatol. 2010; 33(1): $02-07$.

[22] PAHWA P, MCDUFFIE HH, DOSMAN JA. Longitudinal changes in prevalence of respiratory symptoms among Canadian grain elevator workers. Chest. 2006; 129(6): 1605-13. PMid:16778282 http://dx.doi.org/10.1378/chest.129.6.1605

[23] RIBEIRO FSN, WÜNSCH FILHO V. Retrospective assessment of occupational exposure to carcinogens: an epidemiological approach and application to health surveillance. Cad. Saúde Pública. Rio de Janeiro. 2004; 20(4):881-890.

[24] SOARES JFS; CEZAR-VAZ MR; CARDOSO LS. et al. The Risk of the Use of Drugs in the Harbour Work: Study in the Southern Extreme of Brazil. Esc Anna Nery Rev Enferm. 2007; 11(4): 593-8. http://dx.doi.org/10.1590/S1414-81452007000400006 